\title{
POLITECNIA E ENSINO MÉDIO INTEGRADO: APROXIMAÇÕES E DISTANCIAMENTOS ${ }^{1}$
}

\author{
Luciano Marcos Curi; Camila Cunha Oliveira Giordani \\ Programa de Pós-graduação em Educação Profissional e Tecnológica (ProfEPT-IFTM) \\ DOI: 10.15628/rbept.2019.8384 \\ Artigo submetido em mar/2019 e aceito em set/2019
}

\begin{abstract}
RESUMO
O artigo em questão trata do Ensino Médio Integrado dentro do atual debate sobre a aprovação da Lei Federal no 13.415, de 16 de fevereiro de 2017. Tal legislação, a chamada Lei da Reforma do Ensino Médio, alterou a estrutura deste nível de ensino, ignorando experiências brasileiras exitosas, desenvolvidas na última década no nível médio e que, no mínimo, deveriam ter ser ouvidas num debate tão importante. Este estudo se trata, portanto, de uma pesquisa de mestrado, em andamento, que visa demonstrar o mérito do Ensino Médio Integrado (EMI) neste contexto de disputa político-social. Teve como metodologia a pesquisa bibliográfica e documental, fundamentadas em autores como Marx, Manacorda, Saviani, dentre outros, a fim de refletir sobre a finalidade pedagógica e política EMI no âmbito da educação brasileira.
\end{abstract}

Palavras-chave: Ensino Médio. Ensino Médio Integrado. Politecnia. Educação Profissional.

\section{POLYTECHNIC AND INTEGRATED SECONDARY EDUCATION: APPROACHES AND DISTANCES}

\begin{abstract}
The article in question deals with Integrated Secondary Education within the current debate on the approval of Federal Law 13,415, of February 16, 2017. Such legislation, the so-called Law of the Reform of Secondary Education, altered the structure of this level of education, in addition to being dealt with in a context that was not very dialogical. As a result, the government ignored successful Brazilian experiences, developed in the last decade at the middle level, which should at least have to be heard in such an important debate. This study is, therefore, an ongoing master's degree research that aims to demonstrate the merit of Integrated Secondary Education in this context of political-social dispute. Thus, the methodology used was bibliographic and documentary research, based on the legislation of Professional and Technological Education (EPT), as well as authors such as Marx, Manacorda, Saviani, among others, in order to reflect on the pedagogical and political purpose EMI in within Brazilian education.
\end{abstract}

Keywords: Secondary Education. Integrated Secondary Education. Polytechnic. Professional Education.

\footnotetext{
${ }^{1}$ Este artigo originou-se de uma pesquisa de Mestrado do Programa de Pós-graduação em Educação Profissional e Tecnológica (ProfEPT-IFTM).
}

Vol. 2 (2019) 


\section{INTRODUÇÃO}

Nos últimos anos o tema do Ensino Médio tornou-se presente na mídia brasileira. Muito se falou sobre ele, principalmente por ocasião da aprovação da lei federal no 13.415 de 16 de fevereiro de 2017, a chamada Lei da Reforma do Ensino Médio. Esta lei alterou a estrutura do nível médio e foi tramitada num contexto pouco dialógico pelo governo Temer. Primeiramente, editou-se uma Medida Provisória que, depois, foi convertida em lei. Muitos reclamaram deste modo de proceder, inclusive, o Procurador-Geral da República da época, Rodrigo Janot. Especialistas alegaram falta de diálogo tanto com a sociedade quanto com aqueles envolvidos diretamente na área da Educação. Seja como for, tão grave quanto à forma como a lei foi aprovada, é o seu conteúdo que, mesmo após dois anos de sua aprovação, ainda divide opiniões, preocupa os especialistas e estudiosos do nível médio.

Nesse sentido, as inquietações são várias e dentre elas, destaca-se à promessa de soluções que aparentemente o sistema educacional brasileiro não pode oferecer. Também podem ser apontados outros fatores como: a precariedade das escolas brasileiras; a falta de professores; a desvalorização docente; e a ausência de infraestrutura para se trabalhar com os adolescentes, público alvo do nível médio. Estes são problemas que uma lei, por si só, não tem condições de resolver. Portanto, soa demagógica tanto a lei, quanto alguns comerciais que foram veiculados na época da aprovação da chamada "Reforma do Ensino Médio". A flexibilidade de itinerários formativos, propostos pela norma jurídica, parece de difícil execução e, mesmo que seja implantado, fica difícil pensar como ele irá superar problemas estruturais que estão, há décadas, sem solução.

Além disso, o governo ignorou experiências brasileiras exitosas, desenvolvidas na última década no nível médio e que, no mínimo, deveriam ter ser ouvidas num debate tão importante, quando se trata da Educação.

Existem, no Brasil, escolas e modalidades de nível médio bemsucedidas. A pesquisa aqui abordada se refere a um destes exemplos notáveis: trata-se do chamado Integrado ou Ensino Médio Integrado à Educação Profissional (ou ainda, Técnico Integrado ao Ensino Médio) que, desde 2004, existe na forma como hoje o conhecemos.

Portanto, o objetivo desta pesquisa é fazer um estudo histórico e sociológico sobre o Integrado. Para tal, o estudo busca seus fundamentos teóricos em autores como Marx, Manacorda, Saviani, dentre outros, a fim de refletir sobre a finalidade pedagógica e política do Integrado no âmbito da educação brasileira. Trata-se, portanto, de uma pesquisa de mestrado em andamento, em que a metodologia utilizada é a pesquisa bibliográfica e documental.

O presente artigo aponta reflexões sobre o tema e procura contribuir com o atual debate sobre a Reforma do Ensino Médio e, principalmente, sobre as particularidades e singularidades do Integrado. 


\section{DESENVOLVIMENTO}

O Integrado é uma modalidade do nível médio existente no Brasil desde 2004, atualmente bem avaliada em exames e/ou indicadores como IDEB, Pisa e Enem. A imagem massiva, presente nos comerciais governamentais, mostrava a ineficiência desta etapa de ensino em todas as modalidades existentes de nível médio. O Integrado, todavia, se mostra como aquela que, no geral, consegue garantir aos seus estudantes uma preparação para cidadania, articulada com uma forma profissional, e também, à possibilidade de continuar os estudos a nível universitário se o estudante assim o desejar.

A construção, ou criação, do Integrado, porém, é uma luta mais antiga em andamento no Brasil desde a década de 1980: a luta pela Politecnia, ou educação politécnica.

O termo Politecnia ocupa posição de destaque na história desta modalidade. A discussão e a luta pela implantação de uma Educação Politécnica, ou Politecnia, no Brasil são anteriores a 2004, ano em que o Integrado, como conhecido na atualidade, teve seu início. Nesse sentido, para entender adequadamente o percurso e o formato desta modalidade no país, faz-se necessário, antes, conhecer sua base teórica conceitual.

Numa primeira acepção etimológica, o termo Politecnia pode ser entendido como a conjugação de múltiplas técnicas, ou seja, Poli (muitas) e Tecnia (técnicas). Seu significado, porém, não se limita à etimologia da palavra. Desse modo, a Politecnia seria um projeto pedagógico e político de formação humana integral para todos e, principalmente, para os trabalhadores, tradicionalmente desprovidos de uma educação completa desde os primórdios da história humana. A Politecnia, então, seria sinônima de uma formação plena, dita omnilateral, e não de apenas de uma educação limitada a um aspecto, ou seja, unilateral.

É preciso reconhecer, entretanto, que a chamada Educação Politécnica, ou Politecnia, ou ainda Formação Omnilateral, não é um projeto exclusivo da escola marxista. A história da educação registra conceitos semelhantes como a Paideia, dos gregos antigos; o Humanitas, dos romanos, e a Bildung alemã, do século XVII, que também apresentam uma discussão sobre a formação integral do cidadão. Inegavelmente, é preciso reconhecer também que, a teorização marxista ampliou e ultrapassou estes conceitos anteriores de formação humana integral. (OLIVEIRA; OLIVEIRA, 2014).

Segundo Rodrigues (1998), a concepção de Educação Politécnica ocupa espaço considerável nos debates que tratam da relação entre trabalho e educação. Este entendimento, entretanto, não é estranho a pesquisadores nacionais e estrangeiros, havendo entre estes, um consenso de que o conceito de Politecnia advenha dos aportes estabelecidos por Karl Marx, no século XIX.

Antes de tudo, é preciso reafirmar que Marx e Engels não escreveram uma obra exclusiva sobre educação, em seu sentido stricto, porém, uma pesquisa filológica revela uma crítica e uma perspectiva pedagógica nos 
textos de tais autores. Desse modo, seus trabalhos proporcionam, num intervalo de mais de trinta anos, uma dimensão pedagógica que, aliada à história do movimento operário, demonstra a importância para a reflexão da educação nos dias atuais (MANACORDA, 2007).

O processo revolucionário, para Marx, seria a via pela qual o proletariado, consciente de sua ação, deveria percorrer para se chegar à superação das contradições sociais de uma sociedade capitalista. Para a efetivação desse processo, a educação teria um papel importante no desenvolvimento das forças produtivas, sendo o próximo passo, à emancipação proletária (RODRIGUES, 2016). Ou seja, uma formação para a autonomia, para a luta e construção de uma nova sociedade.

Na década de 1980, o Brasil passava por processos de reformulação de suas estruturas político-sociais, revendo as heranças deixadas pela Ditadura Militar, erigidas durante o regime autoritário. Nesse sentido, o cenário educacional brasileiro estava em efervescentes debates sobre novos rumos, passando por momentos catárticos de reanálise de seu passado recente e de instauração novas bases para a reconstrução de uma sociedade democrática (RODRIGUES, 2005).

Nesse contexto, educadores se reuniam, organizando-se coletivamente $^{2}$, com objetivo de debater sobre qual seria o significado social e políticos da educação, principalmente em relação à escola pública, bem como, inquietados em torno de problemas relacionados à questão salarial do magistério (RODRIGUES, 2005).

Dentre as muitas mobilizações ocorridas no movimento de redemocratização do país, estavam às cinco Conferências Brasileiras de Educação (CBE), as quais reforçaram a construção de canais de participação democrática, discutindo e elaborando diretrizes para políticas educacionais orientadas para a maioria da população (RODRIGUES, 2005).

A afluência ocorrida em torno das conferências impulsionaram educadores no processo de produção e reflexão sobre uma nova estrutura para o ensino brasileiro, discutidas durante os debates da Assembleia Nacional Constituinte, à qual procurou encerrar o período da Ditadura Militar e plantar uma nova ordem democrática no Brasil (RODRIGUES, 2005).

Segundo Rodrigues (2005), o desencadeamento do debate brasileiro sobre a Politecnia iniciou-se justamente na década de 1980 fomentado por Dermeval Saviani, a partir de sua atuação no Programa de Pós-Graduação em Educação na Pontifícia Universidade Católica de São Paulo (PUC-SP).

Nesse sentido, Saviani apresenta aos novos pesquisadores em Educação os pensamentos pedagógicos de autores como Marx e Gramsci, principais colaboradores teóricos da perspectiva politécnica de educação (RODRIGUES, 2005). Essas discussões posteriormente influenciaram estudiosos que, num segundo momento, muito contribuíram para a

\footnotetext{
${ }^{2}$ Associação Nacional de Educação (Ande), Associação Nacional de Pós-Graduação e Pesquisa em Educação (Anped), Associação Nacional de Docentes do Ensino Superior (Andes) e as entidades regionais ligadas a então Confederação de Professores do Brasil (CPB) (RODRIGUES, 2005).
} 
disseminação no meio acadêmico brasileiro do conceito de Politecnia, como: Lucília Machado, Acácia Kuenzer e Gaudêncio Frigotto.

Segundo Rodrigues (1998), é possível identificar, nos estudos destes pesquisadores, duas problemáticas principais que, além de definirem seus campos de preocupação, permitem a compreensão das tensões geradas pelos diversos discursos da Politecnia. Uma delas seria de cunho escolar, voltado para a discussão da própria instituição escolar e, a outra, de ordem econômica social, relacionada a questões de âmbito societário.

A obra de Saviani, por exemplo, preocupou-se, primordialmente, no estabelecimento de um sistema nacional de educação. Dessa forma, passando pela caracterização do antigo $2^{\circ}$ Grau (atual Ensino Médio), por meio da (re) construção desta etapa de ensino, é que o autor retomou, debateu e atualizou a concepção de Politecnia (RODRIGUES, 1998).

Com a promulgação da Constituição Federal em 1988 passou-se, na sequência, ao debate sobre as Leis Complementares, ou Leis Regulamentares, que se tornaram necessárias já que a nova constituição instaurara um novo regime democrático no Brasil.

Logo, a questão da Politecnia ou do desenvolvimento omnilateral entraram em pauta na discussão daquela que seria "formalmente" a segunda Lei de Diretrizes e Bases da Educação Nacional (LDB). Desse modo, coube ao professor Dermeval Saviani a produção de um texto ${ }^{3}$ base para a formulação da nova legislação educacional. Tal documento colocava como problemática a constituição de um sistema nacional de educação, em que o Ensino Médio (antigo 2ำ Grau) assumiria destaque.

Isso se devia principalmente pela dificuldade de definição conceitual desta etapa de ensino. É a partir então dessa indefinição, da última etapa da Educação Básica, que o autor pensa a Politecnia, como meio de caracterizar, assim, o Ensino Médio (RODRIGUES, 1998).

Para Saviani (1989, apud Rodrigues 1998), tanto o conceito quanto o trabalho seriam elementos primordiais que organizariam o ensino em geral e os currículos. A definição do nível médio de ensino se daria, então, a partir dessa compreensão. A relação entre trabalho e educação se distinguiria na Educação Básica: no Ensino Fundamental, implícito e indireto, no Ensino Médio, explícito e direto. Assim, "o papel fundamental da escola de nível médio seria, então, o de recuperar essa relação entre o conhecimento e a prática do trabalho" (SAVIANI, 2007, p. 160).

Diferentemente de Saviani, que parte da divisão concreta dos níveis de ensino já existentes no Brasil, Lucília Machado em sua tese de doutoramento intitulada: Unificação escolar e hegemonia (1984) analisa a ideia de "unificação escolar", a partir de uma apreciação histórica da formação dos sistemas unificados de ensino (MACHADO, 1989 apud RODRIGUES, 1998). A autora desenvolveu seu estudo na problemática sobre a Escola Única do trabalho. Dessa maneira, surge a proposta de um ensino politécnico, baseado no projeto socialista de unificação escolar,

\footnotetext{
${ }^{3}$ SAVIANI, Dermeval. Contribuição à elaboração da nova Lei de Diretrizes e Bases da Educação: um início de conversa. 1988. Texto apresentado na XI ANPED. 
contrário às tendências de diferenciação desenvolvidas pelas concepções burguesas de educação. Nesse sentido, Machado incorpora ao debate aberto por Saviani a inquietude em relação à "construção de um novo técnico industrial e a análise do processo de construção dos sistemas nacionais de ensino em duas vertentes: a burguesa e a proletária (escola única do trabalho)" (RODRIGUES, 1998, p. 53).

Em relação aos estudos de Acácia Kuenzer, a autora constrói sua problemática buscando incorporar outro interlocutor notável neste processo, que é o próprio trabalhador, o operário concreto, a partir de duas pesquisas desenvolvidas numa fábrica automobilística, e em escolas secundárias noturnas em Curitiba (KUENZER, 1985, 1986 apud RODRIGUES, 1998). Ao analisar o cotidiano dos funcionários, a autora deduz que o conhecimento produzido na fábrica não dará ao trabalhador a autonomia necessária para compreender os processos e as relações sociais a fim de se superar sua situação de classe. Assim, mudanças curriculares não corrigirão tal deficiência, se não houver a participação do próprio trabalhador, demonstrando a inquietude da autora com a transformação da escola nessa perspectiva (RODRIGUES, 1998). Os aportes da autora são marcados, então, por duas preocupações: tanto relativa ao Ensino Médio, quanto à concepção do aluno-trabalhador, dando especificidade ao pensamento em Educação Politécnica (RODRIGUES, 1998).

Gaudêncio Frigotto, por sua vez, em seu livro: A produtividade da escola improdutiva (1984) resgata pressupostos da Politecnia em autores como Marx, Lênin e Gramsci. Nesse sentido, diferencia-se das demais análises citadas por tentar compreender a totalidade do fenômeno educativo, não restringindo a um determinado nível de ensino. O autor também faz apontamentos importantes em sua obra, como: o desinteresse das classes dominadas pela escola, justificado pelo reflexo das relações econômicopolíticas das classes dominantes sobre os trabalhadores; bem como, o não interesse da burguesia nesse quesito, uma vez que ela dispõe de outros ambientes para se educar (RODRIGUES, 1998).

Rodrigues (2016) identifica, na contribuição teórica dos autores citados, a confluência de três eixos fundamentais, que compõe a concepção de formação politécnica: dimensão infraestrutural, dimensão utópica e dimensão pedagógica.

A primeira dimensão: infraestrutural, diz respeito às mudanças relacionadas às novas formas de organização do processo de trabalho, suas correlatas alterações científicas e tecnológicas (RODRIGUES, 2016).

A segunda dimensão: utópica, tem como objetivo expor a relação próxima entre a concepção de formação humana e um projeto de construção de uma sociedade socialista. Esse projeto utópico-revolucionário impediria um entendimento equivocado da formação politécnica como caminho natural demandado pelo modo de produção capitalista, ao contrário, proporcionaria unidade teórico-política à concepção politécnica de educação (RODRIGUES, 2016).

Em relação à terceira dimensão: pedagógica, Rodrigues (2016) afirma a existência de tensões explícitas entre alguns pesquisadores, no 
quadro da produção teórica brasileira, sobre qual seria o melhor modelo de organização do ensino de caráter politécnico.

Dentre as várias perspectivas, destaca-se àquela que propõe a Politecnia como uma proposta ligada ao Ensino Médio, antigo $2^{\circ}$ Grau. Nesse sentido, para Saviani (1989, apud Rodrigues 1998), tanto o conceito quanto o trabalho enquanto prática seriam elementos primordiais que organizariam este nível de ensino. A definição do nível médio de ensino se daria, então, a partir dessa compreensão. Conforme afirma Saviani (2003):

\begin{abstract}
À medida que o processo escolar se desenvolve, surge a exigência de explicitar os mecanismos que caracterizam o processo de trabalho. Entendo, pois, que o ensino médio deveria já se organizar na forma de uma explicitação da questão do trabalho. (SAVIANI, 2003, p. 136).
\end{abstract}

Segundo Rodrigues (1998), na concepção defendida nos trabalhos realizados por Machado (1984), Kuenzer (1985) e Frigotto (1984) a escola politécnica estaria situada entre a formação fundamental e a formação de nível superior (ou universitária), mas não teria entre seus objetivos a preparação de técnicos de nível médio, ou seja, não ocorreria a especialização nesse momento. Este autor fala ainda da existência de outro grupo de estudiosos que buscavam um contrapeso entre essas duas ideias apresentadas. Para eles, haveria duas etapas: a primeira, em que a formação abarcaria uma compreensão da moderna ciência da tecnologia e do trabalho, e uma segunda, onde ocorreria a profissionalização.

Outro tópico, que também causa discordância entre autores, é em relacionado à terminologia do vocábulo que melhor definiria esta etapa. Em artigo intitulado "Trabalho e educação: fundamentos ontológicos e históricos", Saviani (2007) nos fala que "grosso modo" as expressões "politecnia" e "tecnologia" poderiam ser consideradas em Marx, sinônimas. Entretanto, Nosella (2006 apud SAVIANI, 2007) mostra-se contrário a essa posição quando afirma que "a expressão cautelosa grosso modo não surte efeito, uma vez que as análises de Manacorda são contundentes no destacar a diferença entre as duas expressões para Marx, que atribuía à "moderna ciência da tecnologia" um sentido mais progressista do que a politecnia" (NOSELLA, 2006, p. 11 apud SAVIANI, 2007, p.163).

Saviani (2007), nesse sentido, rebate então a objeção de Nosella e esclarece não ter se atentado à questão etimológica: “(...) para além da questão de termos, isto é, independentemente da preferência pela dominação "educação tecnológica" ou "politecnia", é importante observar que, do ponto de vista conceitual, o que está em causa é um mesmo conteúdo" (SAVIANI, 2007, p. 162). Para Manacorda, em seu livro "Marx e a pedagogia moderna" (2007), uma explicação possível seria a de que, talvez, pelas Escolas Politécnicas terem sido promovidas de forma regrada pelos burgueses, aos filhos dos operários, Marx tenha preferido utilizar este termo com cautela. $O$ próprio autor, porém, afirma que o nome a ser dado à escola do futuro, neste caso, não é o mais importante. Nesse sentido, Manacorda (2007), incorpora 
os dois termos: politecnicismo e tecnologia, considerando ambos importantes para a formação da classe operária:

\begin{abstract}
O primeiro termo (politecnicismo), ao propor uma preparação pluriprofissional, contrapõe-se à divisão do trabalho específica da fábrica moderna; o segundo (tecnologia), ao prever uma formação unificadamente teórico e prática, opõe-se à divisão originária entre trabalho intelectual e trabalho manual, que a fábrica moderna exacerba. O primeiro destaca a idéia da multiplicidade da atividade (a respeito da qual Marx havia falado de uma sociedade comunista na qual, por exemplo, os pintores seriam homens que também pintam) (Marx, 1958, p. 395); o segundo, a possibilidade de uma plena e total manifestação de si mesmo, independentemente das ocupações específicas da pessoa. (MANACORDA, 2007, p.48, palavras adicionadas por mim, grifos do autor).
\end{abstract}

Mediante o exposto, independentemente das diferenças, há certa concordância em relação à formação politécnica como aquela se preocupa com o desenvolvimento integral do homem, que tem no trabalho um aspecto fundamental para sua sobrevivência. Uma educação que se preocupe com sua formação integral, que rompa com a profissionalização restrita e também com uma educação que ignore o trabalho e sua importância. (RODRIGUES, 2016).

Como dito anteriormente, o debate brasileiro sobre o tema exposto esteve bastante ligado ao momento histórico em que o Brasil se encontrava na década de 1980. A discussão sobre a Politecnia atingiu seu ápice no final dos anos 1980 e início dos anos 1990, o que se deveu, sobretudo, pela iminente promulgação da nova Constituição e as discussões que estavam acontecendo no período, face à construção da nova Lei de Diretrizes e Bases para a Educação Nacional (RODRIGUES, 2016).

Promulgada a nova Constituição, os educadores passaram a empreender esforços na elaboração de uma nova LDB. Nela, almejava-se a promoção de uma reforma estrutural baseada não somente em currículos técnicos, mas que dialogasse, ao mesmo tempo, com as demandas sociais e regionais que careciam de atenção (RODRIGUES, 1998).

Devido às transformações que vinham ocorrendo na economia e no mundo do trabalho, desde os anos 1990, a educação profissional começou a ocupar um lugar especial na agenda econômica neoliberal, tão em voga no Brasil e na América Latina, na década de 1990.

Muitos programas políticos e ações governamentais divulgavam que, a qualificação profissional e a formação técnico-profissional, seriam componentes importantes para a inserção do país no grupo de nações designadas como desenvolvidas, além de serem capazes de promover a participação do trabalhador nas novas relações sociais de produção (GRABOWSKY; RIBEIRO, 2010).

Segundo Manfredi (2002), durante a primeira metade dos anos 1990, várias propostas de reestruturação do Ensino Médio e Profissional de diferentes aspirações e grupos sociais foram objeto de debate e 
enfrentamento. Em relação ao governo federal, destacaram-se a existência de dois projetos distintos: o do Ministério da Educação e outro do Ministério do Trabalho. Já no âmbito da sociedade civil, várias entidades de profissionais da educação, de pesquisa, ONGs e entidades do movimento popular e sindical se organizaram no "Fórum em Defesa da Escola Pública" (MANFREDI, 2002). A nova LDB, no entanto, só foi finalizada e promulgada em 20 de dezembro de 1996, oito anos após a promulgação da Constituição.

Neste momento, com o pretexto de que uma nova educação era requerida pela nova ordem econômica mundial e, consequentemente, um novo perfil de trabalhador; após três meses da edição da LDB 9394/96, foi editado, em 17 de abril de 1997, o Decreto no 2.208, reformando a educação profissional no Brasil. Nele foram propostas estratégias de organização e financiamento, diversificação em níveis e modalidades de ensino profissional (GRABOWSKY; RIBEIRO, 2010). Este decreto, no entanto, ia ao sentido contrário do debate até então realizado sobre a Politecnia.

Em 14 de maio de 1997, o Ministério da Educação expede a Portaria no 646, a fim de regulamentar a implantação do disposto nos artigos 39 a 42 da Lei Federal no 9.394/96 e no Decreto Federal oㅜ 2.208/97. Segundo este ato jurídico administrativo, o Ensino Técnico de Nível Médio seria oferecido por meio de:

I - cursos de nível técnico, desenvolvidos concomitantemente com o ensino médio, para alunos oriundos de escolas dos sistemas de ensino;

II - cursos de nível técnico destinados a egressos de nível médio, por via regular ou supletiva;

III - cursos de especialização e aperfeiçoamento para egressos de cursos de nível técnico;

IV - cursos de qualificação, requalificação, reprofissionalização de jovens, adultos e trabalhadores em geral, com qualquer nível de escolarização. (DECRETO 5154/04, Art. 4ํ).

A forma concomitante constante nesta portaria significava que, mesmo estando numa mesma instituição educacional, o aluno poderia ter matrículas distintas, ou seja, uma para o Ensino Médio regular e outra para o Ensino Técnico Profissional. Seriam, então, dois projetos pedagógicos diferentes cumpridos, independentemente, um do outro. O prejuízo seria, nesse caso, o de ter uma educação desarticulada, pela ausência de diálogo entre as disciplinas dentro de um mesmo projeto de curso.

Além disso, esta portaria determinava que a oferta de vagas para cursos de Ensino Médio, nas instituições de Educação Profissional, no ano de 1998, deveria ser reduzida pela metade da oferta disponibilizada em 1997, conforme se pode observar em seu artigo terceiro:

Art. $3^{\circ}$ - As instituições federais de educação tecnológica ficam autorizadas a manter ensino médio, com matrícula independente da educação profissional, oferecendo o máximo de $50 \%$ do total de 
vagas oferecidas para os cursos regulares em 1997, observando 0 disposto na Lei no 9394/96. (PORTARIA MEC 646/1997, Art. 3ㅜ, grifo meu).

Tantas regulamentações na nova LDB no 9394/96, deve-se ao fato de que ela, em seu Capítulo III, "Da Educação Profissional", artigos 39 aos 42, abordava de forma genérica o tema e não trazia especificações da forma que esta modalidade de ensino deveria ser efetivamente viabilizada.

Assim, em 24 de novembro de 1997, o Ministério da Educação, em parceria com o Ministério do Trabalho e Emprego, aprova o Programa de Expansão da Educação Profissional (PROEP). Tal programa também apoiou os segmentos comunitários e definiu, ainda, a iniciativa privada como a principal responsável pela educação profissional (RAMOS, 2010).

Outras ações governamentais também são estabelecidas com o objetivo de cumprir a reforma da educação profissional, conforme afirma Ramos (2010). Paralelamente ao PROEP, outro contrato de empréstimo foi assinado com o Banco Interamericano de Desenvolvimento (BID). Nesse sentido, foi criado o Programa de Melhoria e Desenvolvimento do Ensino Médio (PROMED), voltado para o desenvolvimento de políticas nacionais para o Ensino Médio e de apoio aos sistemas estaduais de ensino. Por trás disto estava o incentivo aos sistemas estaduais de ensino a concentrarem suas ações no nível médio e remeter a oferta da educação profissional a outras instâncias de governo ou diretamente à iniciativa privada (RAMOS, 2010). Tais decisões, todavia, além de não levar em consideração os debates das décadas anteriores sobre a Politecnia, inviabilizou as experiências de ensino que tal concepção poderia proporcionar.

Do ano de 1997, até a primeira eleição de Luiz Inácio Lula da Silva em 2003, pouca coisa se alterou neste cenário. Uma onda neoliberal avolumou-se na sociedade brasileira e não foram emitidas ou reemitidas medidas legislativas que pudesse viabilizar ou concretizar o sonho de uma educação politécnica.

Assim, toda esta conjuntura só se alterou a partir do primeiro governo de Lula, momento no qual se iniciou um debate para reformulação da legislação neoliberal editada no governo anterior. A edição do Decreto 2.208/97 teve um sabor amargo para o debate sobre Politecnia. Ao regulamentar a LDB de 1996, este the altera os rumos, inserindo formatos preferidos da gestão da época e inviabilizou o sonho de um Ensino Médio Politécnico. Portanto, descobriu-se que, naquele momento histórico, fazia-se necessário lutar pela lei e, depois, por sua regulamentação adequada.

Portanto, é importante ressaltar que, até a substituição do Decreto no 2.208/97 pelo Decreto 5.154/04 (em que novas medidas são editadas para a Educação Profissional e Tecnológica), as experiências politécnicas careciam de segurança jurídica no Brasil, pois apesar da anuência da LDB, este decreto não as permitia. É a partir deste período, então, que se vislumbrará a necessidade de um status jurídico diferente. 


\title{
2.1 POLITECNIA E INTEGRADO
}

O surgimento da modalidade de nível médio Integrado emerge então, a partir deste cenário e contexto. Eleito o primeiro governo de Lula, uma de suas bandeiras foi à reformulação da Educação Profissional e Tecnológica noutros moldes diferentes daqueles que haviam sido implementados no governo FHC (1995-2003).

Neste momento, então, ressurge o debate sobre a Politecnia. Contudo, a discussão se depara com um elemento diferenciador que, no geral, pode ser identificada como a realidade brasileira econômica, atinente a maioria dos adolescentes e jovens do país. Ou seja, a ideia de uma preparação geral ou lato sensu para o mundo do trabalho se mostrou, para os analistas e envolvidos na discussão, naquela ocasião, como pouco produtiva ou pouco útil aos jovens brasileiros do início do século XXI. Desse modo, procedeu-se uma adequação à realidade nacional, conforme afirma Moura (2007):

\begin{abstract}
Essa solução é transitória (de média ou longa duração) porque é fundamental que se avance numa direção em que deixe de ser um "luxo" o fato dos jovens das classes populares poderem optar por uma profissão após os 18 anos de idade. Ao mesmo tempo, é viável porque "o ensino médio integrado ao ensino técnico, sob uma base unitária de formação geral, é uma condição necessária para se fazer a 'travessia' para uma nova realidade" (MOURA, 2007, p. 19 apud FRIGOTTO, CIAVATTA e RAMOS, 2005, p. 43).
\end{abstract}

Desse modo, o projeto de uma formação mais completa no nível médio foi mantido. A ele foi adicionado, de maneira articulada, uma habilitação técnica stricto sensu, ou específica. Surgiu, então, uma nova modalidade de ensino, que deveria conter tanto a formação básica quanto a formação técnica num único curso, procurando assegurar, dentro das condições brasileiras, uma formação o mais próxima possível do conceito de Politecnia, tão debatido e discutido nos meios educacionais brasileiros.

Foi neste contexto, e em meio a esses embates entre teoria e realidade, que o Decreto no 2.208/97 foi revogado e substituído pelo Decreto 5.154/04. Este passou a garantir, com a segurança jurídica necessária, uma experiência de Politecnia no Brasil: o Integrado como uma Politecnia à brasileira.

\section{CONSIDERAÇÕES FINAIS}

Este estudo visa esclarecer e reforçar o Integrado como uma singularidade brasileira que se mostra valorosa, que merece uma atenção dos educadores. 
Até o presente momento foram encontradas 26 teses e 143 dissertações elaboradas sobre o Integrado. Constatou-se, nestes trabalhos, uma variedade de abordagens e fundamentos pedagógicos. Verificaram-se, também, numerosas críticas ao que esta modalidade ainda não conseguiu realizar, ou em aspectos que, para serem alterados, careceriam ainda de estudos mais específicos e pontuais. É preciso lembrar, todavia, que, trata-se de uma modalidade com existência de apenas quatorze anos. Precisa, dessa forma, ser pensada, estudada e contemplada também pelo que traz de positivo: a sua proximidade com o projeto politécnico de educação.

Em uma época como a atual onde falar de Reforma de Ensino Médio passou a justificar uma crítica generalizada a tudo que se faz no Brasil no nível médio, repensar o Integrado dentro das particularidades históricas de lutas que lhe deu origem é fundamental.

Portanto, o Integrado não é a modalidade que está crise, que possui índices ruins e é desmotivadora para os jovens, conforme anunciado e criticado nas campanhas publicitárias, veiculadas por ocasião da Reforma do Ensino Médio. Nesse sentido, todos os níveis educacionais e tipos de curso possuem suas dificuldades pedagógicas. Faz-se necessário, no entanto, esclarecimentos de ordem científica tanto para pesquisadores quanto para estudantes e profissionais da educação.

Enfim, o Integrado precisa ser visto também por aquilo que ele é representado: um projeto nacional de ampliação da formação dos adolescentes e jovens do país atento e condizente com a história da Educação Profissional brasileira.

\section{REFERÊNCIAS}

BRASIL. Lei no 9394/96, de 20 de dezembro de 1996: Estabelece as diretrizes e bases da Educação Nacional. Brasília, DF, 1996.

BRASIL. Decreto n. 2.208, de 17 de abril de 1997: Regulamenta o $\S 2^{\circ}$ do art. 36 e os arts. 39 a 42 da Lei no 9.394, de 20 de dezembro de 1996, que estabelece as diretrizes e bases da educação nacional. Brasília, DF, 1997.

BRASIL. Portaria no 646/97, de 14 de maio de 1997: Regulamenta a implantação do disposto nos artigos 39 a 42 da Lei Federal no 9.394/96 e no Decreto Federal oㅡ 2.208/97 e dá outras providências (trata da rede federal de educação tecnológica). Brasília, DF, 1997.

BRASIL. Decreto n. 5.154, de 23 de julho de 2004: Regulamenta o $\S 2^{\circ}$ do artigo 36 e os arts.39 a 41 da Lei n. 9.394, de 20 de dezembro de 1996, que estabelece as diretrizes e bases da educação nacional, e dá outras providências. Brasília, DF, 2004.

BRASIL. Medida Provisória no 746, de 22 de setembro de 2016: Institui a Política de Fomento à Implementação de Escolas de Ensino Médio em Tempo Integral, altera a Lei oㅜ 9.394, de 20 de dezembro de 1996, que estabelece as diretrizes e bases da educação nacional, e a Lei oㅜ 11.494 de 20 de junho 2007, que regulamenta o Fundo de Manutenção e 
Desenvolvimento da Educação Básica e de Valorização dos Profissionais da Educação, e dá outras providências. Brasília, DF, 2016.

BRASIL. Lei no 13415/17, de 16 de fevereiro de 2017: Altera as Leis $\mathrm{n}$ 오 9.394 , de 20 de dezembro de 1996, que estabelece as diretrizes e bases da educação nacional, e 11.494, de 20 de junho 2007, que regulamenta o Fundo de Manutenção e Desenvolvimento da Educação Básica e de Valorização dos Profissionais da Educação, a Consolidação das Leis do Trabalho - CLT, aprovada pelo Decreto-Lei $\mathrm{n}^{\circ}$ 5.452, de 1으 de maio de 1943, e o Decreto-Lei n-236, de 28 de fevereiro de 1967; revoga a Lei $n$ 우11.161, de 5 de agosto de 2005; e institui a Política de Fomento à Implementação de Escolas de Ensino Médio em Tempo Integral. Brasília, DF, 2017.

GRABOWSKI, Gabriel; RIBEIRO, Jorge Alberto Rosa. Reforma, legislação e financiamento da educação profissional no Brasil. In: MOLL, Jaqueline (Org.), et al. Educação Profissional e Tecnológica no Brasil Contemporâneo. Porto Alegre: Artmed, 2010, p. 271-284.

MANFREDI, Silvia Maria. Educação Profissional no Brasil. São Paulo: Cortez, 2002.

MANACORDA, Mario Alighiero. Marx e a pedagogia moderna. Campinas: Editora Alínea, 2007.

MOURA, Dante Henrique. Educação básica e educação profissional e tecnológica: dualidade histórica e perspectiva de integração. Holos, Natal, v.2, p.1-27, 2007. Disponível em:

<http://www2.ifrn.edu.br/ojs/index.php/HOLOS/article/viewFile/11/110>. Acesso em: 29 ago. 2018.

OLIVEIRA, Avelino da Rosa; OLIVEIRA, Neiva Afonso. Modelos de formação humana: paideia, bildung e formação omnilateral. In: BOMBASSARO, Luiz Carlos (Org.), et al. Percursos Hermenêuticos e Políticos. Porto Alegre: UFP/EDIPUCRS/Educs, 2014, p. 208-222.

RAMOS, Marise. Ensino médio integrado: ciência, trabalho e cultura na relação entre educação profissional e educação básica. In: MOLL, Jaqueline (Org.), et al. Educação Profissional e Tecnológica no Brasil

Contemporâneo. Porto Alegre: Artmed, 2010, p. 42-57.

RODRIGUES, José. A educação politécnica no Brasil. Niterói: EdUFF, 1998.

RODRIGUES, José. Por um programa de transcrição para a educação: em defesa da concepção marxista de formação politécnica. In: Organização Escola Politécnica de Saúde Joaquim Venâncio (Org.), et al. Caminhos da Politecnia: 30 anos da Escola Politécnica de Saúde Joaquim Venâncio. Rio de Janeiro: EPSJV, 2016.

RODRIGUES, José. Ainda a educação politécnica: o novo decreto da educação profissional e a permanência da dualidade estrutural. Trabalho, Educação e Saúde, Rio de Janeiro, v.3, n.2, Set. 2005. Disponível em: < http://www.scielo.br/scielo.php?script=sci_arttext\&pid=S1981 -

77462005000200002 >. Acesso em: 13 jan. 2017. 
SAVIANI, Dermeval. O choque teórico da Politecnia. Trabalho, Educação e Saúde, Rio de Janeiro, v.1, n.1, Mar. 2003. Disponível em: < http://www.scielo.br/scielo.php?script=sci_arttext\&pid=S1981$77462003000100010 \&$ Ing=pt\&nrm=iso\&tlng=pt >. Acesso em: 20 jul. 2018.

SAVIANI, Dermeval. Trabalho e educação: fundamentos ontológicos e históricos. Revista Brasileira de Educação, Campinas, v.12, n.32, jan. /abr. 2007. Disponível em: <http://www.scielo.br/pdf/rbedu/v12n34/a12v1234.pdf>. Acesso em: 13 jan. 2017. 